\title{
The safety of liposome bupivacaine following various routes of administration in animals
}

\author{
This article was published in the following Dove Press journal: \\ Journal of Pain Research \\ 30 October 2015 \\ Number of times this article has been viewed
}

\author{
Girish P Joshi' \\ Gary Patou ${ }^{2}$ \\ Vladimir Kharitonov ${ }^{2}$ \\ 'Department of Anesthesiology and \\ Pain Management, University of Texas \\ Southwestern Medical School, Dallas, \\ TX, ${ }^{2}$ Pacira Pharmaceuticals, Inc., \\ Parsippany, NJ, USA
}

Background: This report presents results from four preclinical studies evaluating safety and pharmacokinetics (PKs) of liposome bupivacaine following intravascular (intravenous [IV], intra-arterial [IA]), epidural, and intrathecal administration in dogs.

Methods: Intravascular administration was initially tested in a pilot study to determine maximum tolerated doses, and then in an expanded study of systemic adverse effects and PKs. An epidural study compared properties of liposome bupivacaine alone and in combination with lidocaine/epinephrine vs bupivacaine $\mathrm{HCl}$. Another study assessed effects after intrathecal administration.

Results: In the initial intravascular studies, maximum doses at which no meaningful adverse events were observed with liposome bupivacaine were higher than for bupivacaine $\mathrm{HCl}$ ( $4.5 \mathrm{mg} / \mathrm{kg}$ IV vs $0.75 \mathrm{mg} / \mathrm{kg}$ IV, and $1.5 \mathrm{mg} / \mathrm{kg}$ IA vs $0.1 \mathrm{mg} / \mathrm{kg} \mathrm{IA}$, respectively). In the expanded intravascular study, there was no mortality or changes in pathology; adverse clinical signs included convulsions, lying on side, and decreased muscle tone (all were transient). In the epidural study, liposome bupivacaine was well tolerated at doses up to the highest dose tested (40 mg), with no evidence of spinal cord damage and with less motor blockade than bupivacaine $\mathrm{HCl} 15 \mathrm{mg}$. Intrathecal administration of liposome bupivacaine $40 \mathrm{mg}$ was not associated with meaningful safety concerns and resulted in less motor blockade than bupivacaine $\mathrm{HCl} 15 \mathrm{mg}$. PK analyses showed that maximum plasma bupivacaine levels following administration of liposome bupivacaine $(4.5 \mathrm{mg} / \mathrm{kg} \mathrm{IV}$ and $40 \mathrm{mg}$ epidural) were similar to maximum plasma bupivacaine levels following a threefold lower dose of bupivacaine $\mathrm{HCl}(1.5 \mathrm{mg} / \mathrm{kg}$ IV and $15 \mathrm{mg}$ epidural).

Conclusion: Liposome bupivacaine has a favorable safety profile compared with bupivacaine $\mathrm{HCl}$ when administered to dogs via intravascular, epidural, and intrathecal routes. This favorable safety profile is likely related to the liposome-bound nature of bupivacaine in the liposome bupivacaine formulation.

Keywords: bupivacaine, local anesthesia, spinal injections, drug administration routes

\section{Introduction}

Local and/or regional analgesic techniques are principal components of many multimodal analgesic techniques, as they have been shown to improve pain relief as well as reduce opioid requirements, thereby reducing the potential for opioid-related adverse events. ${ }^{1}$ For many superficial and minimally invasive surgical procedures, local infiltration anesthesia can be used for pain control, while for more involved procedures, regional blockade (peripheral nerve blocks and neuraxial analgesia) with a local anesthetic may be more appropriate. ${ }^{1-3}$

Although local anesthetics generally have favorable safety profiles, ${ }^{4-6}$ unintentional excessive doses of local anesthetics at effect sites can result in serious central 
nervous system (CNS) toxicities (ranging in severity from numbness to convulsions to respiratory depression), and cardiovascular toxicities that can be potentially fatal. ${ }^{4,5,7}$ Neural damage and prolonged sensory and motor deficits have also been reported in human and animal studies when large doses have been administered via epidural or subarachnoid injection. ${ }^{7}$

Bupivacaine liposome injectable suspension (EXPAREL ${ }^{\circledR}$ : Pacira Pharmaceuticals, Inc., Parsippany, NJ, USA) is a liposomal formulation of bupivacaine indicated for single-dose administration into the surgical site to produce postsurgical analgesia. ${ }^{8}$ Bupivacaine is encapsulated in a liposomal formulation as phosphate salt, but concentration is expressed as bupivacaine free base. This needs to be taken into consideration when comparing with traditional formulations such as Marcaine ${ }^{\circledR}$ (AstraZeneca, Sodertalje, Sweden) or Sensorcaine ${ }^{\circledR}$ (Fresenius Kabi USA, Lake Zurich, IL, USA), for which concentration is expressed as bupivacaine $\mathrm{HCl}$. As an example of comparison, $40 \mathrm{mg}$ of bupivacaine base in the liposomal formulation is equivalent in strength to $45 \mathrm{mg}$ of bupivacaine $\mathrm{HCl}^{9}{ }^{9}$

Liposome bupivacaine utilizes DepoFoam ${ }^{\circledR}$ technology (Pacira Pharmaceuticals, Inc.), which consists of an aqueous suspension of multivesicular liposomes organized in a nonconcentric, honeycomb-like structure. ${ }^{10,11}$ The liposomes are made up of multiple drug-containing vesicles. Each vesicle is surrounded by a lipid bilayer that provides mechanical stability and allows for controlled release of drug over several days. As the outermost liposomes rupture, a portion of the encapsulated drug is released. The lipid membranes of the inner vesicles then reorganize, the vesicles enlarge, and eventually release their contents in a successive manner until all of the drug is released. ${ }^{12-14}$ In clinical studies, infiltration of liposome bupivacaine into the surgical site has been shown to provide effective analgesia with reduced opioid consumption for up to 72 hours after surgery across a range of surgical models (eg, soft tissue and orthopedic surgeries). ${ }^{15,16}$ Also, liposome bupivacaine is being investigated for use in peripheral nerve block. ${ }^{17,18}$

Given the increased use and possibility of new indications for liposome bupivacaine, it is important to understand the safety and pharmacokinetic (PK) profiles of this formulation compared with bupivacaine $\mathrm{HCl}$ when administered via atypical routes to assess the potential for toxicity following inadvertent administration. This report presents results from four preclinical studies evaluating safety and PK outcomes with liposome bupivacaine following intravenous (IV), intraarterial (IA), epidural, and intrathecal administration.

\section{Methods}

\section{Animal welfare/ethics}

All four studies used beagle dogs (Canis familiaris) supplied by Marshall BioResources, USA, Inc., North Rose, NY, USA. The study protocols were reviewed and approved by the Institutional Animal Care and Use Committee prior to study initiation. All studies, except the IV/IA dose-finding study, were conducted according to the International Conference on Harmonisation guidelines, in accordance with good laboratory practice (GLP) principles as set forth by the US Food and Drug Administration, Title 21 Code of Federal Regulations Part 58, and as accepted by regulatory authorities in the European Union (Organisation for Economic Cooperation and Development Principles of GLP), Japan (Ministry of Health, Labour and Welfare), and Canada (Canadian Council on Animal Care).

\section{Study designs \\ IV/IA dose-finding study}

The objective of this study was to evaluate potential acute toxicity and determine the maximum tolerated dose (MTD) of liposome bupivacaine after IV or IA administration in five female dogs ( $\sim 9-18$ months of age; $8.7-10.6 \mathrm{~kg}$ ). The study was conducted at Charles River Laboratories, Montreal, Canada. For 12 days prior to the study, animals were acclimated to the laboratory environment and underwent pretreatment health checks. Animals were randomized using a computerized randomization procedure and stratified by body weight. Each conscious, telemetered animal was administered up to four doses of the following study drugs: IV and IA liposome bupivacaine $4.5 \mathrm{mg} / \mathrm{kg}$ and $9.0 \mathrm{mg} / \mathrm{kg}$; IV bupivacaine $\mathrm{HCl}$ $1.0 \mathrm{mg} / \mathrm{kg}, 1.8 \mathrm{mg} / \mathrm{kg}$, and $2.5 \mathrm{mg} / \mathrm{kg}$; or IA bupivacaine $\mathrm{HCl}$ $0.1 \mathrm{mg} / \mathrm{kg}$ and $1.0 \mathrm{mg} / \mathrm{kg}$ (Table 1). A minimum 3-day washout was allowed between each dose. Study drug was administered by IV injection into the saphenous or cephalic veins, or by IA injection via an access port into the carotid artery. Cardiovascular safety outcomes included blood pressure (BP) and electrocardiogram (ECG) waveforms at each dosing; derived parameters were logged as 5-second means from at least 1 hour prior to each dose (baseline) to at least 2 hours after each treatment. Respiratory rate was measured as the average of three assessments at $\leq 2$ minutes, 10 minutes, 30 minutes, and 90 minutes postdose by counting the number of breaths in three 30 -second intervals over a 5 -minute period. No formal statistical evaluations were conducted.

\section{IV/IA expanded study}

Based on results from the dose-finding study, an expanded study was conducted at Charles River Laboratories 
Table I IV/IA study designs

\begin{tabular}{|c|c|c|c|c|}
\hline Test material & Dose I & Dose 2 & Dose 3 & Dose 4 \\
\hline \multicolumn{5}{|l|}{ IV/IA dose-finding study } \\
\hline \multirow[t]{2}{*}{ IV bupivacaine $\mathrm{HCl} 7.5$ mg/mL } & 1.0 mg/kg (Animal I) & 1.0 mg/kg (Animal 3) & $2.5 \mathrm{mg} / \mathrm{kg}$ (Animal I) & 1.8 mg/kg (Animal 2) \\
\hline & & 1.8 mg/kg (Animal I) & & \\
\hline IV liposome bupivacaine $13.3 \mathrm{mg} / \mathrm{mL}$ & $4.5 \mathrm{mg} / \mathrm{kg}$ (Animal 2) & 9.0 mg/kg (Animal 2) & 9.0 mg/kg (Animal 5) & $4.5 \mathrm{mg} / \mathrm{kg}$ (Animal I) \\
\hline IA bupivacaine $\mathrm{HCl} 7.5 \mathrm{mg} / \mathrm{mL}$ & 1.0 mg/kg (Animal 3) & & $0.1 \mathrm{mg} / \mathrm{kg}$ (Animal 3) & \\
\hline \multirow[t]{2}{*}{ IA liposome bupivacaine $13.3 \mathrm{mg} / \mathrm{mL}$} & 4.5 mg/kg (Animal 4) & 9.0 mg/kg (Animal 4) & & 4.5 mg/kg (Animal 3) \\
\hline & Dose level (mg/kg) & $\begin{array}{l}\text { Dose concentration } \\
(\mathrm{mg} / \mathrm{mL})\end{array}$ & $\begin{array}{l}\text { Number of animals, } \\
\text { main study }\end{array}$ & $\begin{array}{l}\text { Number of animals, } \\
\text { recovery study }\end{array}$ \\
\hline \multicolumn{5}{|l|}{ IV/IA expanded study } \\
\hline IV saline control & 0 & 0 & 3 male/3 female & 2 male/2 female \\
\hline IV bupivacaine $\mathrm{HCl}$ & $1.5 / 0.75^{\mathrm{a}}$ & 7.5 & 3 male/3 female & 2 male/2 female \\
\hline IV liposome bupivacaine & 1.5 & 13.3 & 3 male/3 female & 2 male/2 female \\
\hline IV liposome bupivacaine & 4.5 & 13.3 & 3 male $/ 3$ female & 2 male/2 female \\
\hline IA saline control & 0 & 0 & 3 male/3 female & 2 male/2 female \\
\hline IA bupivacaine $\mathrm{HCl}$ & 0.1 & 7.5 & 3 male $/ 3$ female & 2 male $/ 2$ female \\
\hline IA liposome bupivacaine & $\mathrm{I} .5$ & 13.3 & 3 male/3 female & 2 male/2 female \\
\hline IA liposome bupivacaine & $4.5 / 3.0^{b}$ & 13.3 & 3 male/3 female & 2 male/2 female \\
\hline
\end{tabular}

Notes: aAnimals in the recovery study received $1.5 \mathrm{mg} / \mathrm{kg}$; this dose was reduced to $0.75 \mathrm{mg} / \mathrm{kg}$ for animals in the main study based on observed clinical signs; banimals in the recovery study received $4.5 \mathrm{mg} / \mathrm{kg}$; this dose was reduced to $3.0 \mathrm{mg} / \mathrm{kg}$ for animals in the main study based on observed clinical signs.

Abbreviations: IA, intra-arterial; IV, intravenous.

(Montreal, Canada) to further characterize the acute toxicity, including potential reversibility of adverse effects after a 14-day recovery period, and PK properties of liposome bupivacaine compared with bupivacaine $\mathrm{HCl}$. Experiments were conducted in 40 male and 40 female dogs (6-7 months of age; $6.0-10.7 \mathrm{~kg}$ ). Animals were acclimated to the laboratory for at least 21 days. Randomization was stratified by body weight, and male and female animals were randomized separately. Animals were randomized to one of eight treatment groups (ten per group) and received a single dose of the following: IV saline (control); IV bupivacaine $\mathrm{HCl} 0.75 \mathrm{mg} /$ $\mathrm{kg}$ and $1.5 \mathrm{mg} / \mathrm{kg}$; IV liposome bupivacaine $1.5 \mathrm{mg} / \mathrm{kg}$; IV liposome bupivacaine $4.5 \mathrm{mg} / \mathrm{kg}$; IA saline (control); IA bupivacaine $\mathrm{HCl} 0.1 \mathrm{mg} / \mathrm{kg}$; IA liposome bupivacaine $1.5 \mathrm{mg} / \mathrm{kg}$; and IA liposome bupivacaine $3.0 \mathrm{mg} / \mathrm{kg}$ and $4.5 \mathrm{mg} / \mathrm{kg}$ (Table 1). IV doses were administered into the saphenous or cephalic veins; IA doses were administered via an access port into the carotid artery. Blood samples (4 mL) for PK assessments were collected before study drug administration, at 5 minutes, 15 minutes, and 30 minutes after administration, and at 1 hour, 2 hours, 4 hours, and 6 hours after study drug administration and were assayed using a validated high-performance liquid chromatography and mass spectrometry (HPLC/MS) analytical procedure. Key outcomes included general health/mortality, clinical signs, ECG and hemodynamic measures, PK parameters $\left(C_{\max }\right.$, time to $C_{\max }\left[t_{\max }\right]$, area under the concentration-time curve $\left[\mathrm{AUC}_{0-t}\right]$, apparent terminal elimination half-life $\left.\left[t_{1 / 2}\right]\right)$, and histopathology. PK assays measured plasma levels of bupivacaine existing as the free base. Two datasets were analyzed (one for each route of administration [IV and IA]). Homogeneity of the dosing groups within each dataset was assessed using ECG at the 5\% significance level.

\section{Epidural study}

The objectives of this study were to evaluate the potential local and systemic toxicity of liposome bupivacaine (including motor blockade) after epidural administration, and to examine changes to the lumbar spinal cord. The study was conducted at MPI Research Laboratories, Mattawan, MI, USA. Male dogs (5-8 months of age; $6.5-12 \mathrm{~kg}$ ) were acclimated to the laboratory for at least 1 week, and then randomized (six per group) to receive liposome bupivacaine $40 \mathrm{mg}$, liposome bupivacaine $40 \mathrm{mg}$ plus lidocaine $1.5 \%$ (27 mg) with epinephrine 1:200,000, bupivacaine $\mathrm{HCl} 0.5 \% 15 \mathrm{mg}$, DepoFoam placebo, or saline. The liposome bupivacaine plus lidocaine/epinephrine group received lidocaine/epinephrine followed by $0.8 \mathrm{~mL}$ of saline, and then liposome bupivacaine 15 minutes later. Lidocaine has a strong interaction with liposome bupivacaine, and coadministration accelerates release of free bupivacaine from the liposomal vesicles. ${ }^{19}$ DepoFoam placebo had the same lipid composition as liposome bupivacaine but without bupivacaine. At the start of the dosing procedure, dogs were anesthetized using a mixture of nitrous oxide, oxygen, and isoflurane. General anesthesia was maintained with isoflurane and oxygen, as needed. An incision was made, and a 22-gauge spinal 
needle was inserted in the epidural space under fluoroscopic guidance. Treatments were given by a slow bolus $3 \mathrm{~mL}$ injection (0.2 mL/min; L7-S1 vertebrae). Blood samples (2-3 mL) for PK assessment were collected before study drug administration, and at 1 hour, 2 hours, 4 hours, 6 hours, 8 hours, 12 hours, 24 hours, 48 hours, 72 hours, and 96 hours after study drug administration and were assayed using a validated HPLC/MS analytical procedure. Dogs (three per group) were necropsied after 72 hours and after a 2-week observation period. Outcomes included clinical signs, histopathology, and PKs. Clinical signs of impaired hind limb motor function were recorded daily over 22 days to quantify onset, incidence, and reversibility of motor blockade. Spinal cord tissue underlying the injection site was examined using an amino cupric silver stain method to measure the extent of neural degeneration. ${ }^{20}$ Stain intensity was recorded for dorsal, lateral, or ventral funiculi (white matter tracts), or gray matter, on a scale from $1=$ minimal to $5=$ severe. An overall pathology score was assigned to each group using an average of severity scores. A parallel set of hematoxylin-and-eosin-stained cervical, thoracic, and lumbar sections was examined on days 4 and 22 to measure the extent of inflammation and tissue damage; stain intensity was recorded on a scale from $1=$ minimal to $4=$ severe.

\section{Intrathecal study}

The objectives of this study were to compare the local and systemic toxicity of liposome bupivacaine $40 \mathrm{mg}$, bupivacaine $\mathrm{HCl} 0.5 \% 15 \mathrm{mg}$, DepoFoam placebo, and saline after intrathecal injection in dogs (six per group). The study was conducted at MPI Research Laboratories, Mattawan, MI, USA. Male dogs (5-8 months of age; 6.4-12.2 kg) were anesthetized using the same procedure as in the epidural study and randomly assigned to treatment group. A small incision was made over the L3-L4 vertebrae, and a 22-gauge spinal needle was inserted in the intrathecal space under fluoroscopic guidance. Treatments were administered by a slow bolus $3 \mathrm{~mL}$ injection $(0.2 \mathrm{~mL} / \mathrm{min})$. Blood samples $(2-3 \mathrm{~mL})$ for $\mathrm{PK}$ assessment were collected before study drug administration, and at 1 hour, 2 hours, 4 hours, 6 hours, 8 hours, 12 hours, 24 hours, 48 hours, 72 hours, and 96 hours after study drug administration and were assayed using a validated HPLC/MS analytical procedure. The clinical outcomes and assessments in this study were the same as those in the epidural study.

\section{Results}

\section{IV/IA dose-finding study}

The maximum doses at which no severe adverse events were noted were determined to be $1.8 \mathrm{mg} / \mathrm{kg} \mathrm{IV}$ and $0.1 \mathrm{mg} / \mathrm{kg}$
IA for bupivacaine $\mathrm{HCl}$ based on observations of marked increases in BP and heart rate (HR), and clinical signs of decreased activity, prostration, labored breathing, tremors, and convulsions when the dose was pushed higher. The maximum dose of liposome bupivacaine at which no severe adverse events were noted was determined to be $4.5 \mathrm{mg} / \mathrm{kg}$ for both IV and IA administration; a dose of $9 \mathrm{mg} / \mathrm{kg}$ resulted in increased BP and HR, vomiting, and convulsions in some animals. One animal was euthanized due to the severity of adverse effects.

\section{IV/IA expanded study}

At the doses studied (IV bupivacaine $\mathrm{HCl} 0.75 \mathrm{mg} / \mathrm{kg}$ and $1.5 \mathrm{mg} / \mathrm{kg}$, IV liposome bupivacaine $1.5 \mathrm{mg} / \mathrm{kg}$ and $4.5 \mathrm{mg} / \mathrm{kg}$, IA bupivacaine $\mathrm{HCl} 0.1 \mathrm{mg} / \mathrm{kg}$, and IA liposome bupivacaine $1.5 \mathrm{mg} / \mathrm{kg}, 3.0 \mathrm{mg} / \mathrm{kg}$, and $4.5 \mathrm{mg} / \mathrm{kg}$ ), there was no mortality or treatment-related changes in clinical or gross/microscopic pathology. One animal that received bupivacaine $\mathrm{HCl} 1.5 \mathrm{mg}$ IV had sustained convulsions, and other animals treated with this dose showed excessive licking and increased respiratory rate and/or emesis. Tremors and uncoordination were noted in one animal that received bupivacaine $\mathrm{HCl} 0.75 \mathrm{mg} / \mathrm{kg} \mathrm{IV}$. Clinical signs observed with liposome bupivacaine $1.5 \mathrm{mg} / \mathrm{kg}$ or $4.5 \mathrm{mg} / \mathrm{kg}$ IV were generally mild. Increased activity and vocalization were noted in two animals that received liposome bupivacaine $1.5 \mathrm{mg} / \mathrm{kg} \mathrm{IV}$, and no specific treatment-related CNS or motor effects were observed in animals treated with liposome bupivacaine $4.5 \mathrm{mg} / \mathrm{kg} \mathrm{IV}$.

There were no treatment-related observations with bupivacaine $\mathrm{HCl} 0.1 \mathrm{mg} / \mathrm{kg} \mathrm{IA}$. Decreased activity, emesis, and/or uncoordination were observed in dogs treated with liposome bupivacaine $1.5 \mathrm{mg} / \mathrm{kg}$ IA. One animal treated with liposome bupivacaine $3.0 \mathrm{mg} / \mathrm{kg}$ IA had sustained convulsions, salivation, uncoordination, increased vocalization, and increased respiratory rate; other animals treated with this dose showed uncoordination, decreased activity, tremors, salivation, and/ or emesis. Liposome bupivacaine $4.5 \mathrm{mg} / \mathrm{kg}$ IA was associated with convulsions, lying on side, decreased muscle tone, tremors, and/or salivation in two animals, and other animals treated with this dose showed decreased activity, uncoordination, tremors, salivation, and/or emesis. In general, these clinical signs appeared shortly after dosing and resolved within 1 hour.

There were no notable effects on BP, HR, or ECG after administration of bupivacaine $\mathrm{HCl} 0.75 \mathrm{mg} / \mathrm{kg}$ IV or $0.1 \mathrm{mg} / \mathrm{kg} \mathrm{IA}$, or after administration of liposome bupivacaine $1.5 \mathrm{mg}$ IV or IA. No male dogs treated with liposome 
bupivacaine $4.5 \mathrm{mg}$ IV showed any adverse cardiovascular effects; however, one female dog had significantly decreased BP followed by an increase in HR; these effects were transient and resolved by 5 minutes postdosing. The effects of liposome bupivacaine $3.0 \mathrm{mg} / \mathrm{kg}$ IA were variable; one female dog had significant increases in BP and $\mathrm{HR}$, followed by convulsions and increased respiratory rate, another female dog had an increase in HR, and two male dogs had a tendency toward decreased BP. In general, the clinical signs described above appeared shortly after dosing and resolved within an hour. In summary, the maximum doses at which no severe adverse events were noted with IA administration were determined to be $0.1 \mathrm{mg} / \mathrm{kg}$ for bupivacaine $\mathrm{HCl}$ compared with $1.5 \mathrm{mg} / \mathrm{kg}$ for liposome bupivacaine. The maximum doses at which no severe adverse events were noted with IV administration were determined to be $0.75 \mathrm{mg} / \mathrm{kg}$ and $4.5 \mathrm{mg} / \mathrm{kg}$ for bupivacaine $\mathrm{HCl}$ and liposome bupivacaine, respectively (Table 2 ).

Mean bupivacaine PK parameters are shown in Table 3, and plasma bupivacaine levels after IV administration of bupivacaine $\mathrm{HCl} 1.5 \mathrm{mg} / \mathrm{kg}$ and liposome bupivacaine $4.5 \mathrm{mg} / \mathrm{kg}$ are shown in Figure 1. Maximum bupivacaine plasma concentrations were reached 5 minutes postdose for bupivacaine $\mathrm{HCl}$ and 5-15 minutes postdose for liposome bupivacaine. The mean $C_{\max }$ in animals that received IV liposome bupivacaine $4.5 \mathrm{mg} / \mathrm{kg}$ was similar to the mean $C_{\max }$ observed in the IV bupivacaine $\mathrm{HCl} 1.5 \mathrm{mg} / \mathrm{kg}$ group, despite the greater than threefold difference in doses used between the two treatment groups. In general, $t_{1 / 2}$ was shorter with bupivacaine $\mathrm{HCl}$ compared with liposome bupivacaine.

\section{Epidural study}

No evidence of motor block or limb impairment was observed in animals treated with epidural liposome bupivacaine $40 \mathrm{mg}$ alone. In contrast, the majority of animals treated with bupivacaine $\mathrm{HCl} 15 \mathrm{mg}$ (4/6) showed limb impairment that resolved after day 1 (Table 4). Liposome bupivacaine $40 \mathrm{mg}$ plus lidocaine/epinephrine also showed limb impairment that resolved after day $1(5 / 6)$. These effects were consistent with a bupivacaine-related response and were not considered adverse. Some impairment may have been procedural, as

Table 2 Maximum dosages of study drug that were associated with no meaningful adverse events

\begin{tabular}{lll}
\hline $\begin{array}{l}\text { Route of } \\
\text { administration }\end{array}$ & $\begin{array}{l}\text { Bupivacaine } \\
\mathbf{H C l}\end{array}$ & $\begin{array}{l}\text { Liposome } \\
\text { bupivacaine }\end{array}$ \\
\hline Intravenous & $0.75 \mathrm{mg} / \mathrm{kg}$ & $4.5 \mathrm{mg} / \mathrm{kg}$ \\
Intra-arterial & $0.1 \mathrm{mg} / \mathrm{kg}$ & $1.5 \mathrm{mg} / \mathrm{kg}$ \\
\hline
\end{tabular}

one of six animals in the placebo group and two of six in the saline group had transient limb impairment. There was a slight, treatment-related prolongation of activated partial thromboplastin time in dogs receiving bupivacaine $\mathrm{HCl}$ or liposome bupivacaine plus lidocaine/epinephrine.

There was no evidence of any other neuraxial effects. Any red discoloration of the skin subcutis or spinal cord at the injection site was attributed to hemorrhage from needle penetration. Histological findings showed no damage to the spinal cord or adjacent tissues, other than mild local reactions at the needle site as would be expected from the procedural technique. Occasionally, animals that received liposome bupivacaine or placebo had minimal chronic inflammation, characterized by the presence of a few large macrophages with abundant foamy cytoplasm in adipose tissue around nerves. Mean severity scores from silver staining for all treatment groups except liposome bupivacaine plus lidocaine/ epinephrine were at or slightly above the minimal score, indicating that treatment-induced neural degeneration was minimal in all but the bupivacaine plus lidocaine/epinephrine group (Table 5).

PK results showed that plasma bupivacaine disappeared more rapidly when given as bupivacaine $\mathrm{HCl}$ than as liposome bupivacaine (with or without lidocaine/epinephrine) (Figure 2). The depot effect of liposome bupivacaine was evidenced by a similar mean (standard deviation [SD]) $C_{\max }$ in animals receiving liposome bupivacaine $40 \mathrm{mg}$ and those receiving the threefold lower dose of bupivacaine $\mathrm{HCl} 15 \mathrm{mg}$ (319 [504] ng/mL vs 271 [126] ng/mL).

\section{Intrathecal study}

Limb impairment occurred on the day of study drug administration in four of six dogs treated with liposome bupivacaine $40 \mathrm{mg}$; the impairment resolved over the next 1-3 days (Table 4). In the bupivacaine $\mathrm{HCl} 15 \mathrm{mg}$ group, limb impairment was observed on the day of study drug administration in all six dogs, and took up to 8 days to resolve. No dogs in the liposome bupivacaine group experienced respiratory arrest compared with three of six dogs in the bupivacaine $\mathrm{HCl}$ group. There were no differences in the incidence or severity of spinal cord lesions between groups; red skin discoloration at the injection site was presumed to be a result of hemorrhage from needle penetration. Histology staining for degeneration was observed in all sections of the spinal cord, with more degeneration observed in white matter tracts than in the gray matter. Mean severity scores ranged from 1.83 to 2.71 , indicating that lesions were mild to moderate (Table 5). There were 
Table 3 Mean bupivacaine PKs following IV or IA administration of bupivacaine $\mathrm{HCl}$ or liposome bupivacaine

\begin{tabular}{|c|c|c|c|c|c|c|c|c|}
\hline Formulation & $\begin{array}{l}\text { Dose } \\
\text { (mg/kg) }\end{array}$ & Sex & $\begin{array}{l}C_{\max } \\
(\mathrm{ng} / \mathrm{mL})\end{array}$ & $\begin{array}{l}t_{\max } \\
(\min )\end{array}$ & $\begin{array}{l}C_{\max } / \text { dose } \\
(\mathrm{ng} \cdot \mathrm{kg} / \mathrm{mL} / \mathrm{mg})\end{array}$ & $\begin{array}{l}A^{A U C} C_{0-t} \\
(n g \cdot h / m L)\end{array}$ & $\begin{array}{l}\text { AUC }_{0-t} / \text { dose } \\
(\mathrm{ng} \cdot \mathrm{h} / \mathrm{mL} / \mathrm{mg} / \mathrm{kg})\end{array}$ & $\begin{array}{l}t_{1 / 2} \\
\text { (h) }\end{array}$ \\
\hline \multirow[t]{2}{*}{ Bupivacaine $\mathrm{HCl}$ IV } & 1.5 & Female & 2,050 & 5 & 1,370 & 1,110 & 738 & 0.473 \\
\hline & & Male & 2,750 & 5 & $\mathrm{I}, 830$ & 1,320 & 879 & 0.520 \\
\hline \multirow[t]{4}{*}{ Liposome bupivacaine IV } & 1.5 & Female & 782 & 5 & 521 & 1,130 & 751 & I.II \\
\hline & & Male & 1,510 & 5 & 1,000 & 2,260 & 1,510 & 0.800 \\
\hline & 4.5 & Female & $\mathrm{I}, 760$ & 15 & 390 & 3,030 & 674 & 0.839 \\
\hline & & Male & 1,810 & 15 & 402 & 3,720 & 826 & 1.06 \\
\hline \multirow[t]{2}{*}{ Bupivacaine $\mathrm{HCl}$ IA } & 0.1 & Female & 187 & 5 & $\mathrm{I}, 870$ & 62.6 & 626 & 0.267 \\
\hline & & Male & 205 & 5 & 2,050 & 71.1 & 711 & 0.264 \\
\hline \multirow[t]{4}{*}{ Liposome bupivacaine IA } & 1.5 & Female & $\mathrm{I}, 950$ & 5 & $\mathrm{I}, 300$ & $\mathrm{I}, 590$ & 1,060 & $0.47 \mid$ \\
\hline & & Male & 2,070 & 5 & 1,380 & $\mathrm{I}, 740$ & 1,160 & 0.539 \\
\hline & 4.5 & Female & 3,410 & 15 & 758 & 3,560 & 791 & 0.744 \\
\hline & & Male & 5,400 & 15 & 1,200 & 7,450 & 1,650 & 0.787 \\
\hline
\end{tabular}

Abbreviations: AUC, area under the concentration-time curve; $C_{\max }$, maximum plasma concentration; IA, intra-arterial; IV, intravenous; PKs, pharmacokinetics; $t_{1 / 2}$, terminal elimination half-life; $t_{\max }$, time to $C_{\max }$.

no toxicologically relevant differences in total severity scores between groups.

The PK profiles of intrathecally administered liposome bupivacaine and bupivacaine $\mathrm{HCl}$ are shown in Figure 3. Mean [SD] peak bupivacaine plasma concentration was similar for liposome bupivacaine (442 [251] $\mathrm{ng} / \mathrm{mL}$ ) and bupivacaine $\mathrm{HCl}(404[98.3] \mathrm{ng} / \mathrm{mL})$, despite administration of a threefold higher dose of liposome bupivacaine (40 mg vs $15 \mathrm{mg}$ ). After dose normalization, mean [SD] $C_{\max }$ /dose was threefold lower with liposome bupivacaine than bupivacaine $\mathrm{HCl}$ (84.3 [41.7] ng/mL vs 256 [35.6] ng/mL, $P<0.05$ ). Mean [SD] $t_{1 / 2}$ was 14.2 [4.6] hours with liposome bupivacaine compared with $3.25[0.96]$ hours with bupivacaine $\mathrm{HCl}(P<0.05)$.

\section{Discussion}

The American Society of Regional Anesthesia and Pain Medicine (ASRA) recognizes that local anesthetic systemic

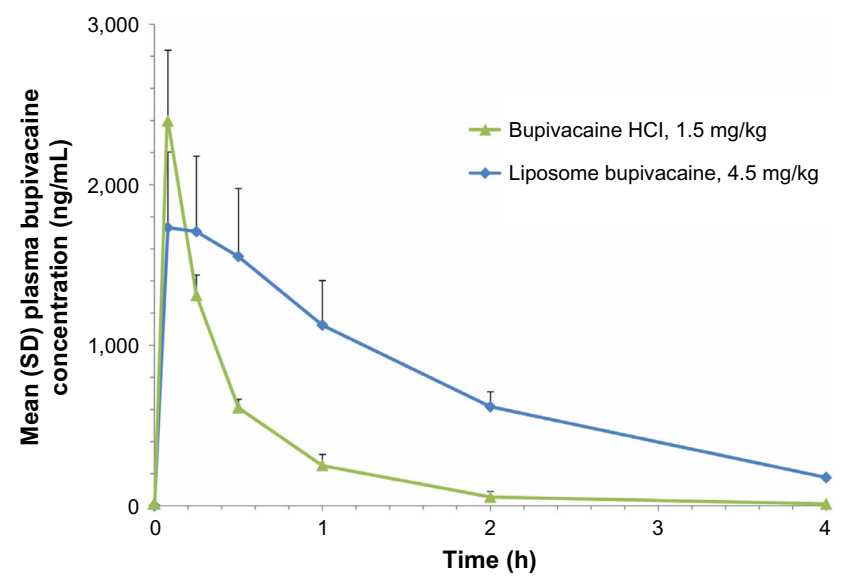

Figure I Plasma bupivacaine pharmacokinetic profile following intravenous administration of bupivacaine $\mathrm{HCl} 1.5 \mathrm{mg} / \mathrm{kg}$ versus liposome bupivacaine $4.5 \mathrm{mg} / \mathrm{kg}$.

Abbreviation: SD, standard deviation. toxicity can result in potentially serious CNS and cardiovascular adverse effects, and recommends using the lowest effective dose of local anesthetics to limit systemic exposure. ${ }^{4}$ In the 2010 practice advisory, ASRA recognized the future potential of sustained-release technologies, such as liposomes, for providing less toxic, longer-acting local anesthetics. ${ }^{4}$ Such technology now exists, and the goal of the studies reported herein was to compare the safety of liposome bupivacaine with that of standard bupivacaine $\mathrm{HCl}$. A range of routes of administration were tested, including IA administration, which is recognized as the most rigorous method for assessing local anesthetic toxicology.

Combined results from both the intravascular dosefinding and expanded studies showed that the MTD of bupivacaine $\mathrm{HCl}$ was $0.75 \mathrm{mg} / \mathrm{kg}$ given IV and $0.1 \mathrm{mg} /$ $\mathrm{kg}$ given IA. Although increased activity and vocalization were noted in the group receiving liposome bupivacaine $1.5 \mathrm{mg} / \mathrm{kg} \mathrm{IV}$, these symptoms were temporary, and no CNS or motor effects were observed in the group receiving $4.5 \mathrm{mg} / \mathrm{kg}$ IV. Therefore, the MTD of liposome bupivacaine was $4.5 \mathrm{mg} / \mathrm{kg}$ when given IV and $1.5 \mathrm{mg} / \mathrm{kg}$ when given IA. Notably, in the dose-finding study, the IA catheter was placed in the carotid artery, resulting in drug delivery directly to the brain, which would not be expected with surgical site infiltration and extremely rare during nerve blocks, assuming that proper precautions are taken. Similarly, IV injection of the entire local anesthetic dose is highly unlikely in routine clinical practice.

Lidocaine is known to interact with liposome bupivacaine and cause a rapid release of free bupivacaine from the liposomal carriers in liposome bupivacaine. ${ }^{19}$ This may explain the observation that higher doses of liposome bupivacaine alone were not associated with clinical signs of 
Table 4 Incidence of neurologic effects (limb impairment) following epidural and intrathecal injection

\begin{tabular}{|c|c|c|c|c|c|c|c|c|c|c|c|c|c|c|c|c|c|}
\hline & \multicolumn{17}{|c|}{ Number of animals with clinical signs of limb impairment ${ }^{a}$} \\
\hline & \multicolumn{17}{|c|}{ Study day (postdosing) } \\
\hline & $\mathbf{I}$ & 2 & 3 & 4 & 5 & 6 & 7 & 8 & 9 & 10 & II & 12 & 13 & 14 & 15 & 16 & 17 \\
\hline \multicolumn{18}{|l|}{ Epidural treatment $(\text { day } \mathrm{I})^{\mathrm{b}}$} \\
\hline Liposome bupivacaine 40 mg & 0 & 0 & 0 & 0 & 0 & 0 & 0 & 0 & 0 & 0 & 0 & 0 & 0 & 0 & 0 & 0 & 0 \\
\hline $\begin{array}{l}\text { Liposome bupivacaine } 40 \mathrm{mg} \\
\text { with lidocaine/epinephrine }\end{array}$ & 5 & 0 & 0 & 0 & 0 & 0 & 0 & 0 & 0 & 0 & 0 & 0 & 0 & 0 & 0 & 0 & 0 \\
\hline Bupivacaine $\mathrm{HCl} 15 \mathrm{mg}$ & 4 & 0 & 0 & 0 & 0 & 0 & 0 & 0 & 0 & 0 & 0 & 0 & 0 & 0 & 0 & 0 & 0 \\
\hline Placebo & 0 & 0 & 0 & 0 & 0 & 0 & 0 & 0 & 0 & 0 & 0 & 0 & 0 & 0 & 0 & 0 & 0 \\
\hline Saline & 0 & 0 & 0 & 0 & 0 & 0 & 0 & 0 & 0 & 0 & 0 & 0 & 0 & 0 & 0 & 0 & 0 \\
\hline \multicolumn{18}{|l|}{ Intrathecal treatment (day I) ${ }^{\mathrm{b}}$} \\
\hline Liposome bupivacaine 40 mg & 4 & 2 & I & 1 & 0 & 0 & 0 & 0 & 0 & 0 & 0 & 0 & 0 & 0 & 0 & 0 & 0 \\
\hline Bupivacaine $\mathrm{HCl}$ I5 mg & 6 & 3 & 3 & 3 & 3 & 3 & 3 & I & 0 & 0 & 0 & 0 & 0 & 0 & 0 & 0 & 0 \\
\hline Placebo & 0 & 1 & I & I & 1 & I & 1 & I & I & 1 & I & 1 & 1 & 1 & 1 & 1 & I \\
\hline Saline & 2 & 2 & I & I & 1 & 0 & 0 & 0 & 0 & 0 & 0 & 0 & 0 & 0 & 0 & 0 & 0 \\
\hline
\end{tabular}

Notes: ${ }^{2}$ No animals had clinical signs of limb impairment beyond day 17 until the last day of observation (ie, day 22); ${ }^{b}$ six male dogs per group.

limb impairment, while limb impairment was observed in most dogs when the same liposome bupivacaine dose was administered in combination with lidocaine/epinephrine, similar to most dogs that received bupivacaine $\mathrm{HCl} 15 \mathrm{mg}$. These results are likely due to differences in local release of unencapsulated bupivacaine between liposome bupivacaine and bupivacaine $\mathrm{HCl}$ as measured by the appearance of bupivacaine in the systemic circulation. Specifically, $C_{\max }$ values of liposome bupivacaine were several-fold lower than comparable and even higher doses of bupivacaine $\mathrm{HCl}$. This suggests that when administered epidurally, the liposome maintains the bupivacaine in a lipid-bound state with insufficient release of free bupivacaine to generate motor blockade. Also, the use of lidocaine followed by liposome bupivacaine can result in bupivacaine toxicity. Of note, three of the 12 animals in the placebo and saline groups showed signs of limb impairment, which may be due to technical issues with epidural placement. Results from the intrathecal study also indicate that a $15 \mathrm{mg} / \mathrm{kg}$ dose of bupivacaine $\mathrm{HCl}$ resulted in more severe, longer-lasting signs of limb impairment than a threefold higher dose $(40 \mathrm{mg})$ of liposome bupivacaine.

The four preclinical studies conducted suggest a differential toxicity profile of liposome bupivacaine when compared with bupivacaine $\mathrm{HCl}$ as manifested by differences in well-tolerated doses observed in the IV and IA studies, and as differences in the propensity for motor blockade in the epidural and intrathecal studies. The explanation for this difference in toxicity could be rooted in the encapsulation of bupivacaine in the liposome bupivacaine formulation compared with the traditional bupivacaine $\mathrm{HCl}$ formulation, in which all bupivacaine exists in a free state. Importantly, the dose of bupivacaine within the liposome delivery system can be much larger than a given dose of traditional bupivacaine $\mathrm{HCl}$ and still present an equal or lower $C_{\max }$. Bupivacaine-related CNS toxicity, cardiac

Table 5 Microscopic observations (silver stain) in lumbar spinal cord after epidural and intrathecal drug administration

\begin{tabular}{|c|c|c|c|c|c|}
\hline & \multicolumn{4}{|c|}{ Mean severity scores (days $4 / 22)^{a}$} & \multirow{2}{*}{$\begin{array}{l}\text { Mean severity } \\
\text { score (all scores) }\end{array}$} \\
\hline & Dorsal funiculus & Lateral funiculus & Ventral funiculus & Gray matter & \\
\hline \multicolumn{6}{|l|}{ Epidural dosing treatment (day I) ${ }^{\mathrm{b}}$} \\
\hline Liposome bupivacaine 40 mg & 1.00 & 1.00 & 0.67 & 1.33 & 1.00 \\
\hline $\begin{array}{l}\text { Liposome bupivacaine } 40 \mathrm{mg} \\
\text { with lidocaine/epinephrine }\end{array}$ & 2.33 & 2.33 & 2.17 & 2.67 & 2.38 \\
\hline Bupivacaine $\mathrm{HCl} 15$ mg & 0.67 & 0.67 & 1.33 & 1.00 & 0.92 \\
\hline Placebo & 0.67 & 1.60 & 1.67 & 1.00 & 1.23 \\
\hline Saline & 1.33 & 0.67 & 0.33 & 0.50 & 0.71 \\
\hline \multicolumn{6}{|c|}{ Intrathecal dosing treatment (day I) } \\
\hline Liposome bupivacaine 40 mg & 2.00 & 2.00 & 2.50 & 0.80 & 1.83 \\
\hline Bupivacaine $\mathrm{HCl} 15$ mg & 3.17 & 2.67 & 2.83 & 2.17 & 2.71 \\
\hline Placebo & 2.83 & 2.83 & 2.83 & 2.17 & 2.54 \\
\hline Saline & 2.50 & 2.50 & 2.67 & 0.83 & 2.13 \\
\hline
\end{tabular}

Notes: aMinimal severity scores excluded (grade I, background staining); bsix male dogs per treatment group. 


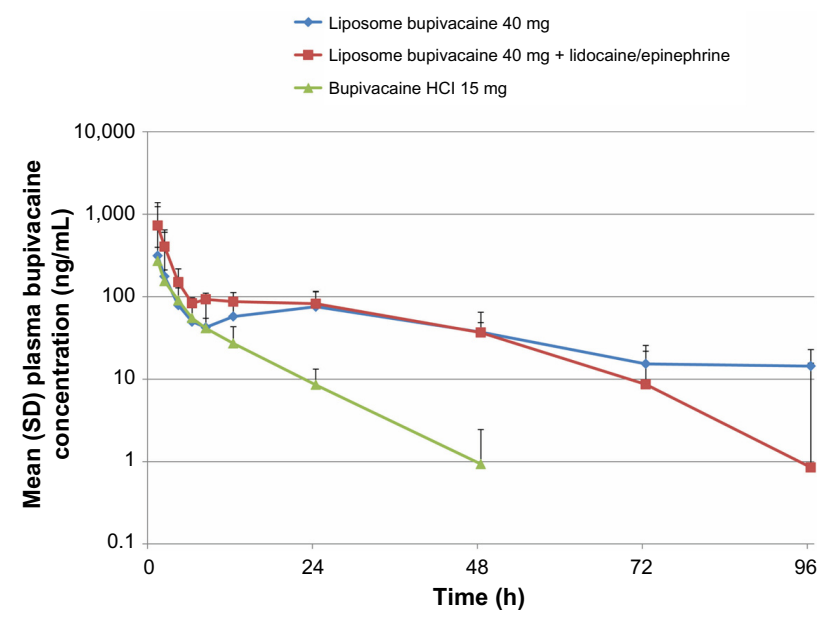

Figure 2 Plasma bupivacaine pharmacokinetic profile following epidural administration of bupivacaine $\mathrm{HCl} 15 \mathrm{mg}$ versus liposome bupivacaine $40 \mathrm{mg}$ (with and without lidocaine/epinephrine).

Abbreviation: SD, standard deviation.

toxicity, and motor blockade are associated with high drug concentrations resulting from exposure to free bupivacaine. Data from the intravascular studies showed that bupivacaine $C_{\max }$ following administration of liposome bupivacaine is one-third of the $C_{\max }$ observed following a comparable dose of bupivacaine $\mathrm{HCl}$, while the overall exposure, as determined by the AUCs, is similar (PK assays measure plasma levels of free bupivacaine). Based on the IV dosing data, we speculate that the liposome bupivacaine particles may potentially be marginated in capillaries or be taken up by the reticuloendothelial system.

Interestingly, the $C_{\max }$ values following epidural administration of higher doses of liposome bupivacaine $(40 \mathrm{mg})$ were similar to $C_{\max }$ values associated with much lower doses of bupivacaine $\mathrm{HCl}(15 \mathrm{mg})$. The overall PK results

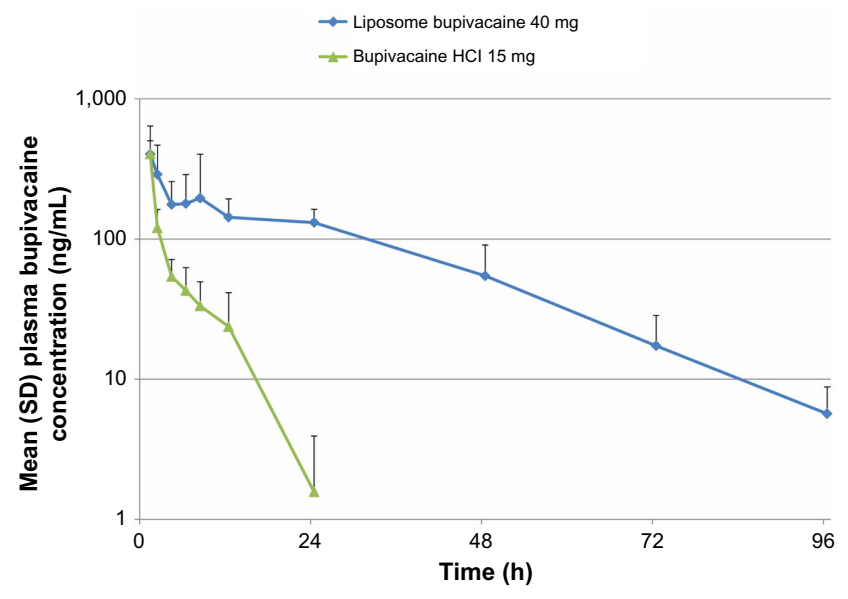

Figure 3 Plasma bupivacaine pharmacokinetic profile following intrathecal administration of bupivacaine $\mathrm{HCl} 15 \mathrm{mg}$ versus liposome bupivacaine $40 \mathrm{mg}$. Abbreviation: SD, standard deviation. of the epidural study suggest that the majority of epidurally administered liposome bupivacaine remains liposome bound and is trapped in the epidural space, while the free fraction of bupivacaine diffuses into the systemic circulation. The inability to perform statistical analysis comparing the groups studied limits the interpretation of the results.

We recognize that clinical observations from animal studies cannot be extrapolated to human populations and should be interpreted with appropriate caution. Nevertheless, results from this preclinical epidural study are consistent with results from an epidural PK study in humans showing that liposome bupivacaine produced prolonged anesthesia without increasing symptoms of motor blockade seen with shorter-acting bupivacaine $\mathrm{HCl}^{21}$

The favorable safety and PK profiles observed in these four preclinical studies are not unexpected. Aside from liposome bupivacaine, DepoFoam technology has been in use for $>15$ years in prolonged-release formulations of medications such as cytarabine (DepoCyt ${ }^{\mathbb{B}}$, Pacira Pharmaceuticals, Inc.) and morphine (DepoDur ${ }^{\mathbb{B}}$, Pacira Pharmaceuticals, Inc.). ${ }^{10,13,14}$ The DepoFoam-based formulations of cytarabine, morphine, and bupivacaine have each been shown to have safety profiles that are similar to standard formulations of the active drug. ${ }^{9,22-24}$

\section{Conclusion}

In conclusion, results from these four preclinical studies suggest that liposome bupivacaine has a favorable safety profile compared with bupivacaine $\mathrm{HCl}$, even when administered via atypical, and often accidental, routes of delivery. The difference in the safety profiles of these two formulations appears to be associated with the liposomebound nature of the bupivacaine within the multivesicular liposomes of the liposome bupivacaine formulation, which allows for the slow release of, and lower exposure to, bupivacaine.

\section{Acknowledgments}

Editorial assistance was provided by Michael D Morren, RPh, of Peloton Advantage, LLC, supported by Pacira Pharmaceuticals, Inc. The authors were fully responsible for the content, editorial decisions, and opinions expressed in the current article. The authors did not receive an honorarium related to the development of this manuscript. This paper was previously presented at 36th Annual American Society of Regional Anesthesia and Pain Medicine (ASRA) Meeting, May 5-8, 2011, Las Vegas, NV, USA, and Experimental Biology and The American Society for Pharmacology and 
Experimental Therapeutics (ASPET) Meeting, April 9-13, 2011, Washington, DC, USA.

\section{Disclosure}

This study was funded by Pacira Pharmaceuticals, Inc. GPJ has received honoraria from Pacira, Mallinckrodt, and Baxter Pharmaceuticals. GP and VK are employees of Pacira Pharmaceuticals, Inc. The authors report no other conflicts of interest in this work.

\section{References}

1. Joshi GP, Schug SA, Kehlet H. Procedure-specific pain management and outcome strategies. Best Pract Res Clin Anaesthesiol. 2014; 28(2):191-201.

2. American Society of Anesthesiologists Task Force on Acute Pain Management. Practice guidelines for acute pain management in the perioperative setting: an updated report by the American Society of Anesthesiologists Task Force on Acute Pain Management. Anesthesiology. 2012;116(2):248-273.

3. White PF, Kehlet H, Neal JM, Schricker T, Carr DB, Carli F. The role of the anesthesiologist in fast-track surgery: from multimodal analgesia to perioperative medical care. Anesth Analg. 2007;104(6):1380-1396.

4. Neal JM, Bernards CM, Butterworth JF 4th, et al. ASRA practice advisory on local anesthetic systemic toxicity. Reg Anesth Pain Med. 2010;35(2):152-161.

5. Di Gregorio G, Neal JM, Rosenquist RW, Weinberg GL. Clinical presentation of local anesthetic systemic toxicity: a review of published cases, 1979 to 2009. Reg Anesth Pain Med. 2010;35(2):181-187.

6. Ilfeld BM. Liposome bupivacaine in peripheral nerve blocks and epidural injections to manage postoperative pain. Expert Opin Pharmacother. 2013;14(17):2421-2431.

7. Covino BG, Wildsmith JA. Clinical pharmacology of local anesthetic agents. In: Cousins MJ, Bridenbaugh PO, editors. Neural Blockade in Clinical Anesthesia and Management of Pain. Philadelphia, PA: Lippincott-Raven; 1998:97-128.

8. Exparel [prescribing information]. Parsippany, NJ: Pacira Pharmaceuticals, Inc.; 2014.

9. Viscusi ER, Sinatra R, Onel E, Ramamoorthy SL. The safety of liposome bupivacaine, a novel local analgesic formulation. Clin J Pain. 2014;30(2):102-110

10. Lambert WJ, Los K. DepoFoam multivesicular liposomes for the sustained release of macromolecules. In: Rathbone MJ, Hadgraft J, Roberts MS, Lane ME, editors. Modified-Release Drug Delivery Technology. New York, NY: Informa Healthcare; 2008:207-214.
11. Chahar P, Cummings KC 3rd. Liposomal bupivacaine: a review of a new bupivacaine formulation. J Pain Res. 2012;5:257-264.

12. Mantripragada S. A lipid based depot (DepoFoam technology) for sustained release drug delivery. Prog Lipid Res. 2002;41(5):392-406.

13. Howell SB. Clinical applications of a novel sustained-release injectable drug delivery system: DepoFoam technology. Cancer J. 2001; 7(3):219-227.

14. Angst MS, Drover DR. Pharmacology of drugs formulated with DepoFoam $^{\mathrm{TM}}$ : a sustained release drug delivery system for parenteral administration using multivesicular liposome technology. Clin Pharmacokinet. 2006;45(12):1153-1176.

15. Bergese SD, Ramamoorthy S, Patou G, Bramlett K, Gorfine SR, Candiotti KA. Efficacy profile of liposome bupivacaine, a novel formulation of bupivacaine for postsurgical analgesia. J Pain Res. 2012;5: 107-116.

16. Schmidt WK, Patou G, Joshi GP. Evaluating therapeutic benefit in postsurgical analgesia requires global assessment: an example from liposome bupivacaine in hemorrhoidectomy. Hosp Pract. 2012;40(1):160-165.

17. Minkowitz H, Matthews A, Puckett C, Melson T. Liposome bupivacaine in femoral nerve block: initial results from a phase $2 / 3$ pivotal study. Poster presented at: Annual Meeting of the American Society of Regional Anesthesia and Pain Medicine; April 3-6, 2014; Chicago, IL.

18. Ilfeld BM, Malhotra N, Furnish TJ, Donohue MC, Madison SJ. Liposomal bupivacaine as a single-injection peripheral nerve block: a dose-response study. Anesth Analg. 2013;117(5):1248-1256.

19. Kharitonov V. A review of the compatibility of liposome bupivacaine with other drug products and commonly used implant materials. Postgrad Med. 2014;126(1):129-138.

20. Switzer RC 3rd. Application of silver degeneration stains for neurotoxicity testing. Toxicol Pathol. 2000;28(1):70-83.

21. Viscusi ER, Candiotti KA, Onel E, Morren M, Ludbrook GL. The pharmacokinetics and pharmacodynamics of liposome bupivacaine administered via a single epidural injection to healthy volunteers. Reg Anesth Pain Med. 2012;37(6):616-622.

22. Carvalho B, Roland LM, Chu LF, Campitelli VA 3rd, Riley ET. Singledose, extended-release epidural morphine (DepoDur) compared to conventional epidural morphine for post-cesarean pain. Anesth Analg. 2007;105(1):176-183.

23. Gambling D, Hughes T, Martin G, Horton W, Manvelian G. A comparison of Depodur ${ }^{\mathrm{TM}}$, a novel, single-dose extended-release epidural morphine, with standard epidural morphine for pain relief after lower abdominal surgery. Anesth Analg. 2005;100(4):1065-1074.

24. Glantz MJ, LaFollette S, Jaeckle KA, et al. Randomized trial of a slow-release versus a standard formulation of cytarabine for the intrathecal treatment of lymphomatous meningitis. J Clin Oncol. 1999;17(10):3110-3116.
Journal of Pain Research

\section{Publish your work in this journal}

The Journal of Pain Research is an international, peer-reviewed, open access, online journal that welcomes laboratory and clinical findings in the fields of pain research and the prevention and management of pain. Original research, reviews, symposium reports, hypothesis formation and commentaries are all considered for publication.

\section{Dovepress}

The manuscript management system is completely online and includes a very quick and fair peer-review system, which is all easy to use. Visit http://www.dovepress.com/testimonials.php to read real quotes from published authors. 